\title{
FAKTOR - FAKTOR YANG MEMPENGARUHI PERTUMBUHAN ASET BANK SYARIAH DI INDONESIA TAHUN 2006-20151]
}

\author{
Diamantin Rohadatul Aisy \\ Program Studi Ekonomi Islam Fakultas Ekonomi dan Bisnis Universitas Airlangga \\ Email: diamantinais@yahoo.com \\ Imron Mawardi \\ Departemen Ekonomi Syariah Fakultas Ekonomi dan Bisnis Universitas Airlangga \\ Email: imron.mawardi@feb.unair.ac.id
}

\begin{abstract}
:
This research aimed to determine the external and internal factors affect to the assets growth of Islamic banking in Indonesia, in time year 2006 until year 2015. The approach is a quantitative approach using PLS (Partial Least Square) analytical techniques with three latent variables, that is external factors as an exogenous variable wich which used to reflect external factors in this research are inflation, GDP Growth, Bl rate, and money supply ( $\left.\mathrm{M}_{2}\right)$; internal factors as an endogenous variable which are reflected by profit sharing rate, promotion, education and training cost, NPF ratio, ROA ratio, FDR ratio, Third-Party Funds, quantity of office bank, and office channeling; and assets growth of Islamic banking as an endogenous variable. The result of this research showed that external factors has a significant effect to internal factors. However, both external factors and internal factors have no significant effect to the growth of Islamic banking asset.
\end{abstract}

\section{Keywords: External, Internal, Asset Growth, Islamic Banking}

\section{PENDAHULUAN}

Fenomena perkembangan industri perbankan syariah di Indonesiayang diukur dengan pertumbuhan aset, menunjukkan adanya kenaikan yang signifikan pada tahun 2005 hingga 2012 (Tabel 1). Adanya perkembangan yang pesat tersebut dikarenakan adanya dukungan regulasi pemerintah. Selain itu, menurut Alamsyah (2012), adanya keunggulan yang dimiliki oleh sistem kevangan syariah di Indonesia, yang tidak dimiliki oleh negara Islam lainnya, memberikan kontribusi dalam perkembangan industri perbankan syariah di Indonesia. Adapun faktorfaktor lain yang mendukung perkembangan industri perbankan syariah di Indonesia yaitu antara lain ekspansi jaringan kantor bank syariah, serta gencarnya program edukasi dan sosialisasi yang dilakukan oleh Bank Indonesia. Namun, fenomena pertumbuhan aset bank syariah yang meningkat tersebut tidak terjadi pada tahun 2012 hingga tahun 2015 (Tabel 1), dimana tingkat pertumbuhan aset bank syariah terus mengalami penurunan. Oleh karena itu, perlu dilakukan 
Aisy, et al/Jurnal Ekonomi Syariah Teori dan Terapan Vol. 3 No. 3 Maret 2016: 249-265; FAKTOR-FAKTOR YANG MEMPENGARUHI PERTUMBUHAN ASET BANK SYARIAH DI INDONESIA TAHUN 2006-2015

penelitian untuk dapat mengetahui faktor-faktor yang sebenarnya mempengaruhi pertumbuhan aset bank syariah di Indonesia.

Tabel 1.

Pertumbuhan Aset Bank Syariah di Indonesia Tahun 2004-2015

\begin{tabular}{|c|c|c|}
\hline & $\begin{array}{c}\text { Aset } \\
\text { (miliar Rp) }\end{array}$ & G Aset (\%) \\
\hline Des-03 & 7.859 & \\
\hline Des-04 & 15.326 & $95,01 \%$ \\
\hline Des-05 & 20.880 & $36,24 \%$ \\
\hline Des-06 & 26.722 & $27,98 \%$ \\
\hline Des-07 & 36.538 & $36,73 \%$ \\
\hline Des-08 & 49.555 & $35,63 \%$ \\
\hline Des-09 & 66.090 & $33,37 \%$ \\
\hline Des-10 & 97.519 & $47,55 \%$ \\
\hline Des-11 & 145.467 & $49,17 \%$ \\
\hline Des-12 & 195.018 & $34,06 \%$ \\
\hline Des-13 & 242.276 & $24,23 \%$ \\
\hline Des-14 & 272.343 & $12,41 \%$ \\
\hline Jun-15 & 272.389 & $0,02 \%$ \\
\hline Sumber: Stan $\%$ \\
\hline
\end{tabular}

Sumber: Statistik Perbankan Syariah, 2003-

2015, Otoritas Jasa keuangan.

Mengacu pada penelitian sebelumnya yang dilakukan oleh Syafrida dan Ahmad (2011), terdapat beberapa faktor yang mempengaruhi pertumbuhan aset bank syariah, yaitu faktor Office Channeling, jumlah vang beredar $\left(M_{2}\right)$, jumlah kantor, rasio NPF, biaya promosi, pendidikan dan pelatihan, jumlah DPK, serta rasio FDR.
Sedangkan menurut penelitian yang dilakukan Indriani (2006), faktor-faktor yang mempengaruhi pertumbuhan aset bank syariah meliputi faktor pertumbuhan GDP, suku bunga riil, inflasi, rasio ROA, jumlah kantor, serta rasio NPF. Oleh karena itu, berdasar pada penelitian sebelumnya, adapun faktor eksternal yang diteliti meliputi indikator inflasi, pertumbuhan GDP, BI rate, dan jumlah vang beredar $\left(M_{2}\right)$, sedangkan faktor internal yang diteliti meliputi indikator tingkat bagi hasil, biaya promosi, pendidikan dan pelatihan, rasio NPF, rasio ROA, rasio FDR, jumlah DPK, jumlah kantor, serta office channeling.

Berdasarkan uraian yang telah dijelaskan, maka peneliti dapat merumuskan masalah penelitian sebagai berikut: Apakah faktor eksternal berpengaruh terhadap faktor internal; Apakah faktor eksternal berpengaruh terhadap pertumbuhan aset bank syariah di Indonesia; serta Apakah faktor internal berpengaruh terhadap pertumbuhan asetb bank syariah di Indonesia?

\section{LANDASAN TEORI}

Karim (2007:139) menjelaskan adanya pengaruh buruk inflasi terhadap perekonomian, salah satunya yaitu melemahkan semangat dan sikap menabung masyarakat (turunnya Marginal Propensity to Save); serta berakibat pada pengarahan investasi pada hal-hal yang non produktif yang berupa penumpukkan 
Aisy, et al/Jurnal Ekonomi Syariah Teori dan Terapan Vol. 3 No. 3 Maret 2016: 249-265; FAKTOR-FAKTOR YANG MEMPENGARUHI PERTUMBUHAN ASET BANK SYARIAH DI INDONESIA TAHUN 2006-2015

kekayaan (hording) seperti tanah, bangunan, logam mulia, mata uang asing, dengan mengorbankan investasi ke arah produktif seperti pertanian, industrial, perdagangan, transportasi, dan lainnya. Berdasar pada pemikiran tersebut, dapat disimpulkan bahwa meningkatnya inflasi akan berakibat pada penurunan jumlah kewajiban dan dana syirkah temporer, sehingga secara tidak langsung akan menurunkan total aset yang dimiliki oleh bank syariah.

Mishkin (2009:59) menjelaskan bahwa pertumbuhan ekonomi yang stabil secara langsung akan mendorong perusahaan untuk berinvestasi atau mendorong orang untuk menabung. Hal tersebut dikarenakan pertumbuhan ekonomi berkaitan erat dengan penyediaan lapangan kerja, dimana dunia usaha lebih mungkin menginvestasikan pada peralatan modal untuk meningkatkan produktivitas dan pertumbuhan ekonomi ketika pengangguran rendah. Sebaliknya, jika pengangguran tinggi dan pabrik-pabrik tidak digunakan, maka perusahaan akan menunda untuk berinvestasi dalam pabrikpabrik dan peralatan tambahan.

Muhammad (2004:44) menyebutkan adanya faktor-faktor yang mempengaruhi manajemen dana di bank, salah satunya yaitu kebijaksanaan-kebijaksanaan moneter, terutama yang terkait dengan penghimpunan dana. Kebijaksanaan yang biasa dikeluarkan oleh bank sentral tersebut salah satu contohnya adalah tingkat suku bunga Bank Indonesia atau BI rate. Selanjutnya tingkat suku bunga tersebut harus dipatuhi oleh bank dan diterapkan dalam bentuk pengaturan dan persyaratan yang tentunya berbeda untuk masingmasing bentuk simpanan masyarakat, seperti tabungan, deposito, tabungan haji, serta produk penghimpunan dana lainnya. Kebijaksanaan tingkat suku bunga bank merupakan upaya peningkatan penghimpunan dana dalam rangka mengimbangi peningkatan perkreditan yang juga ditargetkan oleh bank sentral, sehingga dapat meminimalisir dampak inflasi yang ditimbulkan, serta menjaga kestabilan nilai rupiah. Sehingga dapat disimpulkan bahwa tingkat suku bunga bank atau BI rate yang ditentukan oleh bank sentral dapat membantu perbankan dalam peningkatan dana pihak ketiganya, dimana hal tersebut juga akan berimplikasi pada tingkat inflasi dan nilai rupiah yang stabil.

Muhammad (2004:47), adanya pengaruh jumlah vang beredar terhadap inflasi dikarenakan dana yang ada di masyarakat dan diperebutkan oleh lembaga-lembaga keuangan sifatnya terbatas. Adapun ketersediaan dana yang ada di masyarakat tersebut dipengaruhi oleh jumlah ekspansi vang primer dari bank sentral. Oleh karena itu, dapat disimpulkan bahwa vang yang 
Aisy, et al/Jurnal Ekonomi Syariah Teori dan Terapan Vol. 3 No. 3 Maret 2016: 249-265; FAKTOR-FAKTOR YANG MEMPENGARUHI PERTUMBUHAN ASET BANK SYARIAH DI INDONESIA TAHUN 2006-2015

beredar di masyarakat dapat mempengaruhi jumlah dana yang dihimpun oleh bank, termasuk bank syariah pada khususnya. Secara tidak langsung, hal tersebut akan mempengaruhi dana titipan dan kuasi ekuitas yang merupakan komponen penyusun aset bank syariah.

Mishkin (2008:128) menjelaskan dalam Teori Permintaan Aset (theory of asset demand) bahwa jumlah permintaan aset berhubungan positif dengan perkiraan imbal hasil relatif terhadap aset alternatif. Secara singkat dapat disimpulkan bahwa para pemilik dana tertarik untuk menyimpan dana di bank berdasarkan tingkat bunga atau tingkat bagi hasil yang dijanjikan (Muhammad, 2005:264).

Bauran pemasaran (marketing mix) dalam aspek promosi, menurut Muhammad (2005:234) meliputi promosi penjualan, iklan/advertising, hubungan masyarakat (humas), pemasaran langsung, dan publishing. Aspek bauran pemasaran (marketing mix) lainnya yang menjadi aspek penting dalam pemasaran adalah produk. Aspek produk beberapa hal dimana salah satunya adalah kualitas dan pelayanan. Menurut Muhammad (2005:237), pelayanan yang baik, cepat, dan tidak bertele-tele menjadi syarat mutlak dalam memberikan layanan kepada nasabahnya dan masyarakat. Hal tersebut dilakukan oleh bank dalam rangka pemenuhan kebutuhan pasar.
Adanya pemenuhan kebutuhan pasar yang berpengaruh pada daya beli hasil dari pemasaran produk, dapat diukur dengan pencapaian target volume penjualan. Adapun komponen volume penjualan yang dimaksud salah satunya mencakup dana pihak ketiga (funding) yang dapat dilihat dari jumlah dana yang dapat dikumpulkan pada suatu periode. Hal ini membuktikan adanya pengaruh secara tidak langsung biaya promosi, pendidikan dan pelatihan yang menjadi bagian dari biaya pemasaran, terhadap peningkatan dana pihak ketiga yang merupakan komponen sumber dana atau aset bank syariah.

Rasio Non-Performing Financing (NPF) adalah rasio pembiayaan bermasalah terhadap total pembiayaan. Rasio ini digunakan untuk mengukur tingkat permasalah pembiayaan yang dihadapi oleh bank, khususnya untuk mengetahui proporsi pembiayaan bermasalah terhadap total pembiayaan yang diberikan oleh bank (Bank Indonesia, 2012:179). Dimana jumlah pembiayaan bermasalah merupakan jumlah pembiayaan yang tergolong dalam kolektibilitas Kurang Lancar, Diragukan, dan Macet, sesuai dengan ketentuan Bank Indonesia yang didasarkan atas penilaian beberapa faktor, meliputi prospek usaha, kinerja (performance) nasabah, dan kemampuan membayar. Semakin tingginya nilai rasio NPF menunjukkan kualitas 
Aisy, et al/Jurnal Ekonomi Syariah Teori dan Terapan Vol. 3 No. 3 Maret 2016: 249-265; FAKTOR-FAKTOR YANG MEMPENGARUHI PERTUMBUHAN ASET BANK SYARIAH DI INDONESIA TAHUN 2006-2015

pembiayaan bank syariah yang semakin buruk (Bank Indonesia, 2012:179).

Laba bank syariah, menurut Muhammad (2005:264), tidak hanya berpengaruh terhadap tingkat bagi hasil untuk para pemegang saham, tetapi juga berpengaruh terhadap bagi hasil yang diberikan kepada nasabah pemilik dana, dimana tingkat bagi hasil kemudian akan dapat mempengaruhi jumlah dana pihak ketiga yang mampu dihimpun oleh bank syariah. Hal tersebut dikarenakan para pemilik dana tertarik untuk menyimpan dana di bank berdasarkan tingkat bunga atau bagi hasil yang dijanjikan. Sehingga dapat juga dilihat pengaruh tidak langsung antara laba bank syariah yang dalam diukur dengan Return on Assets (ROA), terhadap dana/aset bank syariah yang dimiliki oleh bank syariah.

Berdasar pada penelitian yang dilakukan oleh Syafrida dan Ahmad (2011:7), dibuktikan adanya pengaruh signifikan rasio FDR terhadap pertumbuhan aset perbankan syariah di Indonesia. Hal ini dikarenakan peningkatan FDR yang akan mengurangi likuiditas pada bank syariah, sehingga jumlah aset lancar bank menjadi berkurang dan aset secara total juga akan berkurang.

Pertumbuhan setiap bank sangat
dipengaruhi oleh perkembangan
kemampuannya menghimpun dana
masyarakat, baik berskala kecil maupun

besar, dengan masa pengendapan yang memadai (Muhammad, 2004:49). Hal tersebut menjelaskan bahwa dana pihak ketiga atau dana yang dihimpun dari masyarakat merupakan elemen penting yang harus diperhatikan bank dalam rangka meningkatkan pertumbuhan bank. Seperti yang dijelaskan sebelumnya juga, bahwa salah satu komponen dana atau aset bank syariah yaitu dana titipan atau dana pihak ketiga, maka dapat disimpulkan bahwa peningkatan maupun penurunan jumlah dana pihak ketiga yang mampu dihimpun oleh bank syariah akan secara langsung mempengaruhi jumlah aset bank syariah beserta pertumbuhannya.

Berdasar pada penelitian sebelumnya yang dilakukan oleh Indriani (2006:79), menyatakan bahwa adanya peningkatan jumlah kantor bank syariah akan berpengaruh signifikan terhadap pertumbuhan total aset bank syariah di Indonesia. Hal ini disebabkan karena pertumbuhan kantor bank syariah di negara-negara yang sedang berkembang akan lebih mudah dicapai atau lebih pesat, dimana pertumbuhan kantor bank syariah tersebut akan menimbulkan tingkat kesulitan yang relatif tinggi bagi cabang bank asing untuk memasuki industri perbankan. Hal ini sejalan pula dengan penjelasan Antonio dalam Indriani (2006:79), bahwa luasnya jumlah jaringan kantor akan meningkatkan efisiensi usaha dan 
Aisy, et al/Jurnal Ekonomi Syariah Teori dan Terapan Vol. 3 No. 3 Maret 2016: 249-265; FAKTOR-FAKTOR YANG MEMPENGARUHI PERTUMBUHAN ASET BANK SYARIAH DI INDONESIA TAHUN 2006-2015

meningkatkan kompetisi ke arah peningkatan kualitas pelayanan dan mendorong inovasi produk dan jasa perbankan syariah. Adanya peningkatan efisiensi usaha yang diikuti dengan peningkatan kualitas pelayanan ini akan membantu bank syariah dalam memperluas jangkauan pelayanan kepada masyarakat, sehingga bank syariah dapat lebih terjangkau oleh masyarakat yang ingin menggunakan jasa bank syariah, dalam hal ini salah satunya yaitu penitipan dana masyarakat. Sehingga, pada akhirnya secara tidak langsung peningkatan jumlah kantor bank syariah akan meningkatkan jumlah dana yang mampu dihimpun oleh bank, yang selanjutnya akan dijadikan aset oleh bank syariah untuk disalurkan kepada masyarakat deficit unit atau maysarakat yang membutuhkan dana.

Seperti pada industri perbankan pada umumnya, bank syariah juga dituntut untuk mempunyai kebijakan terkait pengembangan perbankan yang mengarah pada peningkatan efisiensi dan profesionalisme. Peningkatan efisiensi tersebut dapat berupa pemanfaatan teknologi tepat guna maupun peningkatan peningkatan pelayanan serta perluasan jangkauan pelayanan, dimana hasil yang diharapkan adalah kepercayaan masyarakat terhadap perbankan yang meningkat (Muhammad, 2004:46). Kepercayaan masyarakat tersebut dapat berupa penitipan dana di bank, khususnya bank syariah, yang akan berimplikasi langsung pada peningkatan dana pihak ketiga dan kuasi ekuitas yang dihimpun oleh bank. Kedua sumber dana tersebut merupakan komponen penyusun dana atau aset bank syariah, sehingga layanan syariah atau officechanneling yang pada bank syariah secara tidak langsung akan berpengaruh pada total aset yang dimiliki bank.

Muhammad (2004:44) menjelaskan bahwa manajemen dana bank sangat dipengaruhi oleh kebijaksanaan moneter, artinya setiap muncul kebijaksanaan moneter yang baru, bank harus mengambil langkah-langkah penyesuaian agar tidak melanggar peraturan atau ketinggalan di bidang kevangan dan perekonomian pada umumnya. Selain itu, kebijakan-kebijakan yang diambil pemerintah, terutama kebijakan di bidang perkreditan, diarahkan untuk mendorong dan meningkatkan kemampuan para pengusaha golongan ekonomi lemah, sehingga harus dipastikan bank dapat menyediakan kredit/pembiayaan dalam jumlah yang memadai dengan tingkat suku bunga yang wajar, namun juga harus diimbangi dengan kebijakan di bidang penghimpunan dana berupa penciptaan inovasi produk agar tidak menimbulkan dampak inflasi. 
Aisy, et al/Jurnal Ekonomi Syariah Teori dan Terapan Vol. 3 No. 3 Maret 2016: 249-265; FAKTOR-FAKTOR YANG MEMPENGARUHI PERTUMBUHAN ASET BANK SYARIAH DI INDONESIA TAHUN 2006-2015

\section{METODE PENELITIAN}

Penelitian ini meneliti hubungan pengarh antara tiga variabel, yaitu faktor eksternal sebagai variabel laten eksogen (X $\left.X_{1}\right)$, dengan indikator inflasi, pertumbuhan GDP, $\mathrm{BI}$ rate, dan Uang Beredar $\left(\mathrm{M}_{2}\right)$;faktor internal sebagai ariabel laten endogen intervening $\left(Y_{1}\right)$, dengan indikator tingkat bagi hasil ekuivalen, biaya promosi, pendidikan dan pelatihan, rasio NPF, rasio ROA, rasio FDR, jumlah DPK, jumlah kantor, dan Office Channeling; serta pertumbuhan aset bank syariah sebagai Variabel Endogen $\left(Y_{2}\right)$. Pengujian dilakukan dengan metode Partial Least Square, dikarenakan metode PLS dapat mentoleransi adanya multikoliniertias dalam model, serta dapat meneiliti pengaruh antar variabel yang memiliki dukungan teori yang lemah (Ghozali, 2008:4).

\section{Definisi Operasional Variabel}

\section{Faktor Eksternal}

Faktor eksternal bank syariah yang dimaksud dalam penelitian ini adalah faktor-faktor yang berasal dari unsur-unsur di luar wilayah bank syariah, namun dapat berpotensi mempengaruhi bank syariah.

\section{Faktor Internal}

Faktor internal adalah faktor-faktor yang mencakup unsur-unsur di dalam bank syariah, serta digunakan untuk menentukan suatu tujuan dan strategi tertentu dari bank syariah.

\section{Pertumbuhan Aset Bank Syariah}

Pertumbuhan aset bank syariah yang dimaksud dalam penelitian ini merupakan data jumlah aset bank syariah diperoleh dari Statistik Perbankan Syariah (SPS) yang dirilis resmi oleh Otoritas Jasa Keuangan (OJK) melalui website www.ojk.go.id dalam bentuk triwulan selama periode tahun 2006 sampai tahun 2015, yang kemudian dihitung tingkat pertumbuhannya dengan rumus sebagai berikut:

Asset Growth (\%) $=\left(\right.$ Assets $_{+}-$Asset $\left._{t-1}\right)$ :

$$
\text { Asset }_{t-1} \times 100 \%
$$

Dimana:

$$
\begin{aligned}
& \dagger=\text { Waktu } \dagger \text { (triwulan) } \\
& t^{-1}=\text { Waktu sebelum } \dagger \text { (triwulan } \\
& \text { sebelum } \dagger \text { ) }
\end{aligned}
$$

\section{Jenis dan Sumber Data}

Jenis data yang digunakan dalam penelitian ini adalah data kuantitatif yang berjenis data sekunder.Data yang digunakan merupakan jenis data time series triwulan mulai periode triwulan I tahun 2006 hingga truwilan II tahun 2015. Data didapat dari website resmi Bank Indonesia (www.bi.go.id), Otoritas Jasa Keuangan (www.ojk.go.id), dan Badan Pusat Statistik (www.bps.go.id).

\section{Teknik Analisis}

Penelitian ini menguji pengaruh antar variabel laten yang tidak memiliki ukuran pasti dan hanya diukur dengan beberapa indikator.Oleh karena itu, pengujian hipotesis dalam penelitian ini menggunakan 
Aisy, et al/Jurnal Ekonomi Syariah Teori dan Terapan Vol. 3 No. 3 Maret 2016: 249-265; FAKTOR-FAKTOR YANG MEMPENGARUHI PERTUMBUHAN ASET BANK SYARIAH DI INDONESIA TAHUN 2006-2015

metode Partial Least Square (PLS). Berikut analisis yang dilakukan dalam metode PLS:

\section{Evaluasi Model}

Terdapat dua tahap dalam evaluasi model yang dilakukan dalam penelitian ini, yaitu evaluasi outer model dan evaluasi inner model. Evaluasi outer model atau model pengukuran bertujuan untuk melihat hubungan antara observed variabel atau indikator dengan variabel laten. Sedangkan evaluasi inner model atau model struktural bertujuan untuk melihat hubungan antar variabel laten yang dihipotesiskan (Latan dan Ghozali, 2013:75).

\section{Model Pengukuran (Outer Model)}

Model pengukuran atau outer model dilakukan untuk menilai validitas dan reliabilitas. Uji validitas dapat dilihat dari nilai outer loading antara indikator dan variabel laten yang dicerminkan. Ukuran refleksif indikator dikatakan cukup nilai loading 0.5 sampai 0.6 dianggap cukup (Chin dalam Ghozali, 2008:24). Sedangkan, uji reliabilitas dapat dilihat dari nilai composite reliability dan Average Variance Extracted (AVE) masing-masing konstruk antara indikator dan variabel laten yang dicerminkan. Model dinyatakan Composite reliability mengukur internal consistency dan model dinyatakan reliable apabila nilainya di atas 0.60. Sedangkan untuk nilai AVE, model dinyatakan reliable apabila nilainya di atas 0.50 .

\section{Model Struktural (Inner Model)}

Model struktural dievaluasi dengan melihat besarnya presentase variance yang dijelaskan yaitu dengan melihat nilai RSquares untuk variabel laten endogen, dan Stone-Geisser test untuk menguji predictive relevance (Q-square) (Ghozali, 2008:26). Semakin besar nilai R-Squares, maka semakin besar presentase variabel laten endogen yang dijelaskan oleh model. Dalam spesifik angka menurut Hair et al. (2011) dalam Latan dan Ghozali (2013:83), 0.75 menunjukkan model kuat, 0.55 menunjukkan model moderate, dan 0.25 menunjukkan model lemah. Sedangkan, untuk Predictive relevance $\left(Q^{2}\right), Q^{2}>0$ menunjukkan model mempunyai predictive relevance, dan $Q^{2}<0$ menunjukkan model kurang memiliki predictive relevance.

\section{Uji Hipotesis}

Pengujian hipotesis pada penelitian ini dilakukan pada second order contruct (inner model) dengan menggunakan uji $\dagger$ dan signifikansi dari koefisien parameter jalur (Path Coefficient). Nilai signifikansi t-statistik menggambarkan besarnya pengaruh antar variabel. Berikut hipotesis dan aturan pengambilan keputusan, pada tingkat keyakinan 95\% ( $a=0.05)$ sebagai berikut.

Hipotesis:

$\begin{aligned} \mathrm{H}_{0}: \mathrm{Y}_{\mathrm{i}} & =0, \text { variabel laten eksogen } \\ & \text { berpengaruh tidak signifikan } \\ & \text { terhadap variabel laten } \\ & \text { endogen }\end{aligned}$




$\begin{array}{rlr}\mathrm{H}_{a}: \mathrm{Y}_{i} & \neq 0 \text { variabel laten eksogen } \\ & \text { berpengaruh } & \text { signifikan } \\ & \text { terhadap variabel laten } \\ & \text { endogen } & \end{array}$

Pengambilan keputusan:

Jika t-statistik < 1.96 atau p-value $>0.05$, maka $\mathrm{H}_{0}$ diterima

Jika t-statistik $>1.96$ atau p-value $\leq 0.05$, maka Ho ditolak

\section{HASIL DAN PEMBAHASAN}

Hasil pengujian validitas model variabel laten menggunakan nilai outer loading, seperti pada Tabel 2, menunjukkan adanya indikator yang tidak valid karena memiliki nilai outer loading di bawah 0.5. Adapun indikator yang tidak valid adalah indikator pertumbuhan GDP pada variabel laten faktor eksternal dengan nilai loading sebesar 0.351, serta indikator rasio FDR dan rasio ROA pada variabel laten faktor internal, dengan nilai loading masingmasing sebesar 0.339 dan 0.179. Ketiga indikator yang tidak vali tersebut harus dibuang agar model menjadi baik dan valid, serta kemudian model diestimasi ulang.

Tabel 2.

Uji Validitas Model Pertama

\begin{tabular}{|c|c|c|c|}
\hline & $\begin{array}{c}\text { Original } \\
\text { Sample }\end{array}$ & $\begin{array}{c}\mathbf{P} \\
\text { Values }\end{array}$ & Ket. \\
\hline $\begin{array}{c}\text { GDP <- } \\
\text { Faktor } \\
\text { Eksternal }\end{array}$ & 0.351 & 0.281 & $\begin{array}{l}\text { Tidak } \\
\text { Valid }\end{array}$ \\
\hline FDR <- & -0.399 & 0.007 & Tidak \\
\hline
\end{tabular}

\begin{tabular}{|c|c|c|c|}
\hline $\begin{array}{c}\text { Faktor } \\
\text { Internal }\end{array}$ & & & Valid \\
\hline $\begin{array}{c}\text { ROA <- } \\
\text { Faktor } \\
\text { Internal }\end{array}$ & -0.179 & 0.523 & $\begin{array}{l}\text { Tidak } \\
\text { Valid }\end{array}$ \\
\hline
\end{tabular}

Sumber: Output SmartPLS 3.0 (diolah).

Setelah model diestimasi ulang dengan menghilangkan indikator pertumbuhan GDP, rasio FDR, dan rasio ROA, didapatkan hasil yang valid untuk semua indikator dalam model, seperti pada tabel 3 . Sehingga dapat disimpulkan bahwa indikator valid atau tepat untuk digunakan sebagai instrumen pengukuran suatu variabel laten yang dicerminkan.

Tabel 3.

Outer Loading Model Kedua

\begin{tabular}{|c|c|c|c|}
\hline & $\begin{array}{l}\text { Original } \\
\text { Sample }\end{array}$ & $\begin{array}{c}P \\
\text { Values }\end{array}$ & Ket. \\
\hline $\begin{array}{c}\text { INF <- Faktor } \\
\text { Eksternal }\end{array}$ & -0.769 & 0.000 & Valid \\
\hline $\begin{array}{c}\text { BI <- Faktor } \\
\text { Eksternal }\end{array}$ & 0.810 & 0.000 & Valid \\
\hline $\begin{array}{c}\text { M2 <- Faktor } \\
\text { Eksternal }\end{array}$ & 0.831 & 0.000 & Valid \\
\hline $\begin{array}{c}\text { BH <- Faktor } \\
\text { Internal }\end{array}$ & -0.720 & 0.000 & Valid \\
\hline $\begin{array}{c}\text { BPPP <- } \\
\text { Faktor } \\
\text { Internal }\end{array}$ & 0.679 & 0.000 & Valid \\
\hline $\begin{array}{c}\text { NPF <- Faktor } \\
\text { Internal }\end{array}$ & 0.737 & 0.000 & Valid \\
\hline $\begin{array}{c}\text { DPK }<- \text { Faktor } \\
\text { Internal }\end{array}$ & 0.875 & 0.000 & Valid \\
\hline
\end{tabular}




\begin{tabular}{|c|c|c|c|}
\hline $\begin{array}{c}\text { JKB <- Faktor } \\
\text { Internal }\end{array}$ & 0.944 & 0.000 & Valid \\
\hline $\begin{array}{c}\text { OC <- Faktor } \\
\text { Internal }\end{array}$ & 0.641 & 0.000 & Valid \\
\hline $\begin{array}{c}\text { PA <- } \\
\text { Pertumbuhan } \\
\text { Aset }\end{array}$ & 1.000 & Valid \\
\hline
\end{tabular}

Sumber: Output SmartPLS 3.0 (diolah).

Selain itu, persamaan model pengukuran (outer model) juga dapat dibentuk berdasarkan pada nilai original sample (O). Adapun persamaan yang menggambarkan model pengukuran pada penelitian ini adalah sebagai berikut.

a. Variabel laten eksogen (reflektif) Inflasi $=-0.769$ Faktor Eksternal $+\delta_{1.1}$ $\mathrm{BI}$ Rate $=0.810$ Faktor Eksternal $+\delta_{1.2}$ Jumlah Uang Bereda $\mathrm{M}_{2}=0.839$ Faktor Eksternal $+\delta_{1.3}$

b. Variabel laten endogen intervening (reflektif)

Tingkat Bagi Hasil $=-0.720$ Faktor Internal $+\delta 2.1$

Biaya Promosi, Pendidikan dan Pelatihan $=0.679$ Faktor Internal $+\delta_{2.2}$

Rasio NPF $=0.737$ Faktor Internal $+\delta_{2.3}$ Jumlah Dana Pihak Ketiga $=0.875$ Faktor Internal $+\delta_{2.4}$

Jumlah Kantor $=0.944$ Faktor Internal + $\delta_{2.5}$

Jumlah Layanan Syariah $=0.641$ Faktor Internal $+\delta_{2.6}$
Selanjutnya, untuk menilai reliabilitas model, maka yang pertama digunakan output tabel Composit Reliability dan Average Variance Extracted (AVE). Berdasarkan pengukuran composit reliability, pada Tabel 4, variabel laten faktor eksternal tidak reliabel karena memiliki nilai di bawah 0.60, yaitu sebesar 0.417. Hal ini berarti bahwa hasil pengukuran faktor eksternal pada waktu yang berbeda pada kelompok subjek yang sama kurang dapat dipercaya, atau dapat menimbulkan perbedaan. Namun, berbeda halnya dengan hasil uji reliabilitas berdasarkan nilai Average Variance Extracted (AVE), dimana ketiga variabel laten memiliki nilai AVE di atas 0.50. Hal tersebut menunjukkan bahwa indikator reliabel jika digunakan pada waktu yang berbeda pada kelompok subjek yang sama.

Tabel 4.

Composite Reliability dan Average Variance Extracted (AVE)

\begin{tabular}{|c|c|c|c|c|}
\hline & $\begin{array}{c}\text { Composite } \\
\text { Reliability }\end{array}$ & Ket. & AVE & Ket. \\
\hline $\begin{array}{c}\text { Faktor } \\
\text { Eksternal }\end{array}$ & 0.417 & $\begin{array}{c}\text { Tidak } \\
\text { Valid }\end{array}$ & 0.646 & Valid \\
\hline $\begin{array}{c}\text { Faktor } \\
\text { Internal }\end{array}$ & 0.805 & Valid & 0.599 & Valid \\
\hline $\begin{array}{c}\text { Pertumbuhan } \\
\text { Aset }\end{array}$ & 1.000 & Valid & 1.000 & Valid \\
\hline
\end{tabular}

Sumber: Output SmartPLS 3.0 (diolah).

Berikut nilai R-square untuk variabel endogen Pertumbuhan Aset Bank Syariah 
Aisy, et al/Jurnal Ekonomi Syariah Teori dan Terapan Vol. 3 No. 3 Maret 2016: 249-265; FAKTOR-FAKTOR YANG MEMPENGARUHI PERTUMBUHAN ASET BANK SYARIAH DI INDONESIA TAHUN 2006-2015

(Y2) dan variabel endogen intervenning Faktor Internal $\left(Y_{1}\right)$.

Tabel 5.

R-Square Variabel Laten Endogen

\begin{tabular}{|l|c|}
\hline & Original Sample \\
\hline Faktor Eksternal & - \\
\hline Faktor Internal & 0.762 \\
\hline Pertumbuhan Aset & 0.015 \\
\hline
\end{tabular}

Sumber: Output SmartPLS 3.0 (diolah).

Berdasarkan pada Tabel 4.6. di atas, dapat diketahui bahwa dalam model pengaruh faktor eksternal dan internal terhadap pertumbuhan aset bank syariah, sebesar Sedangkan, variabel Faktor Internal sebagai variabel endogen intervenning dapat dijelaskan oleh variabel Faktor Eksternal sebesar 76.2\%. Namun hanya sebesar $1.5 \%$ variabel Pertumbuhan Aset Bank Syariah dapat dijelaskan oleh variabel Faktor Eksternal dan Faktor Internal. Berdasarkan pada hasil tersebut, dapat disimpulkan bahwa baik variabel laten endogen intervenning Faktor Internal memiliki model struktural (inner model) yang baik. Sebaliknya, variabel laten endogen Pertumbuhan Aset Bank Syariah memiliki model yang lemah.

Selanjutnya, nilai Q-square untuk perhitungan Stone-Geisser Q-square test didapat melalui perhitungan sebagai berikut:

$$
\begin{aligned}
& Q^{2}=1-\left\{\left(1-R^{2}\right)\left(1-R^{2}\right) \ldots . .\left(1-R^{2} p\right)\right\} \\
& Q^{2}=1-\left\{\left(1-0.762^{2}\right)\left(1-0.015^{2}\right)\right\} \\
& Q^{2}=1-\{(0,4193)(0,9998)\} \\
& Q^{2}=1-0,4192
\end{aligned}
$$

$$
Q^{2}=0,5808
$$

Berdasarkan perhitungan di atas, nilai Qsquare pada model ini adalah 0,5808. Sehingga dapat disimpulkan bahwa model ini memiliki nilai predictive relevance yang cukup.

Selanjutnya, berikut output uji $\dagger$ dan signifikansi dari koefisien parameter jalur (path coefficient):

Tabel 6.

Path Coefficient Variabel Laten

\begin{tabular}{|l|c|c|c|c|}
\hline & $\begin{array}{c}\text { Original } \\
\text { Sample }\end{array}$ & $\begin{array}{c}\text { T } \\
\text { Statistics }\end{array}$ & $\begin{array}{c}\mathbf{P} \\
\text { Values }\end{array}$ & Ket. \\
\hline $\begin{array}{l}\text { Faktor } \\
\text { Eksternal -> } \\
\text { Faktor } \\
\text { Internal }\end{array}$ & -0.873 & 34.277 & 0.000 & Sig. \\
\hline $\begin{array}{l}\text { Faktor } \\
\text { Eksternal -> } \\
\text { Pertumbuhan }\end{array}$ & 0.053 & 0.140 & 0.889 & $\begin{array}{l}\text { Tdk } \\
\text { Aset }\end{array}$ \\
\hline $\begin{array}{l}\text { Faktor } \\
\text { Internal -> } \\
\text { Pertumbuhan } \\
\text { Aset }\end{array}$ & -0.072 & 0.193 & 0.847 & $\begin{array}{l}\text { Tdk } \\
\text { Sig. }\end{array}$ \\
\hline
\end{tabular}

Sumber: Output SmartPLS 3.0

(diolah).

Berdasarkan tabel di atas, dapat diketahui bahwa:

1. Pengaruh faktor eskternal terhadap faktor internal memiliki nilai $p$-value< 0.05 yaitu 0.000 , maka $\mathrm{H}_{1}$ diterima. Hal ini berarti faktor eksternal mempengaruhi faktor internal secara signifikan sebesar -0.873 . 
Aisy, et al/Jurnal Ekonomi Syariah Teori dan Terapan Vol. 3 No. 3 Maret 2016: 249-265; FAKTOR-FAKTOR YANG MEMPENGARUHI PERTUMBUHAN ASET BANK SYARIAH DI INDONESIA TAHUN 2006-2015

2. Pengaruh faktor internal terhadap faktor pertumbuhan aset bank syariah memiliki nilai $p$-value $>0.05$, yaitu 0.889 , maka $\mathrm{H}_{2}$ ditolak. Hal ini berarti faktor eksternal tidak mempengaruhi pertumbuhan aset bank syariah.

3. Pengaruh faktor internal terhadap pertumbuhan aset bank syariah memiliki $p$-value< 0.05 , yaitu 0.847 , maka $\mathrm{H}_{3}$ ditolak. Hal ini berarti faktor internal tidak mempengaruhi pertumbuhan aset bank syariah.

Adapun persamaan model struktural yang dibentuk oleh ketiga variabel laten adalah sebagai berikut:

$$
\begin{aligned}
Y_{2} & =0.053 \text { Faktor Eksternal }+\varsigma_{1} \\
Y_{2} & =-0.072 X_{2}+\varsigma_{1} \\
& =-0.072(-0.873 \text { Faktor Eksternal })+\varsigma_{1} \\
Y_{2} & =0.063 \text { Faktor Eksternal }+\varsigma_{1}
\end{aligned}
$$

\section{Pembahasan}

Adanya pengaruh faktor eksternal terhadap faktor internal didominasi oleh indikator $\mathrm{Bl}$ rate dan jumlah vang beredar (M2) dengan nilai outer loading terbesar. BI rate mencerminkan faktor eksternal sebesar 0.810 , sedangkan jumlah uang beredar $\left(\mathrm{M}_{2}\right)$ mencerminkan faktor eksternal sebesar 0.831. Selain kedua indikator tersebut, indikator lainnya yang juga mencerminkan faktor eksternal adalah indikator inflasi sebesar -0.769 .

Hal ini menunjukkan bahwa adanya perubahan faktor eksternal, baik berupa tingkat suku bunga, jumlah uang beredar
$\left(\mathrm{M}_{2}\right)$, tingkat inflasi, maupun pertumbuhan GDP, akan mempengaruhi internal bank syariah, salah satunya berupa kebijakankebijakan baru terkait manajemen internal bank syariah, sebagai respon atas perubahan faktor eksternal, seperti perubahan jumlah vang beredar $\left(\mathrm{M}_{2}\right)$ dan Bl rate yang akan mempengaruhi kebijakan bank syariah terkait dengan nisbah bagi hasil pendanaan. Ketika jumlah vang beredar $\left(M_{2}\right)$ di maysarakat tinggi, maka Bank Indonesia akan menentukan tingkat $\mathrm{Bl}$ rate yang tinggi. Mengikuti hal tersebut, suku bunga yang diterapkan di bank konvensional juga akan meningkat. Dalam rangka menghindari displacement commercial risk, maka bank syariah akan menyesuaikan nisbah bagi hasil, agar nominal tingkat pengembalian yang diterima nasabah mampu setara dengan bunga yang diterima nasabah bank konvensional.

Perubahan-perubahan faktor eksternal, seperti tingkat inflasi, suku bunga Bank Indonesia, maupun jumlah vang beredar $\left(M_{2}\right)$, akan direspon oleh seluruh lembaga penyedia jasa keuangan, termasuk juga bank syariah dan bank konvensional. Sehingga, kebijakan-kebijakan baru tidak hanya akan dikeluarkan oleh bank syariah, namun sebagai respon dari faktor eksternal, bank konvensional juga akan mengelvarkan kebijakan-kebijakan terkait produk-produk yang dimiliki. Adanya respon 
Aisy, et al/Jurnal Ekonomi Syariah Teori dan Terapan Vol. 3 No. 3 Maret 2016: 249-265; FAKTOR-FAKTOR YANG MEMPENGARUHI PERTUMBUHAN ASET BANK SYARIAH DI INDONESIA TAHUN 2006-2015

terhadap perubahan faktor eksternal juga akan dilakukan oleh lembaga kavangan lainnya, seperti lembaga mikro, asuransi, pegadaian, pasar modal, dan lembagalembaga lainnya. Adanya respon dari seluruh lembaga penyedia jasa keuangan atas perubahan faktor eksternal, membuat masyarakat tidak ada preferensi untuk beralih ke lembaga keuangan lainnya.

Selain itu, dimungkinkan adanya indikator lain yang mencerminkan variabel faktor eksternal, yang tidak terdapat dalam model, yaitu faktor agama atau preferensi masyarakat untuk menggunakan produk bank syariah berdasarkan pemahamannya terhadap prinsip Islam. Gait dalam Adawiyah (2010:192) menyatakan bahwa terdapat penelitian yang dilakukan oleh Omer (1992), Metwally (1996), Metawa dan Almossawi (1998), Al-Sultan (1999), serta Bley dan Kuehn (2004), menemukan sebagian besar responden memilih agama sebagai faktor utama yang memotivasi mereka dalam menggunakan produk dan jasa perbankan syariah. Oleh karena itu, faktor agama memungkin menjadi faktor yang mempengaruhi jumlah dana pihak ketiga yang dihimpun oleh bank syariah, sehingga juga berpengaruh terhadap pertumbuhan aset bank syariah di Indonesia, serta berada di luar model.

Terdapat indikator faktor internal yang memungkinkan adanya pengaruh terhadap pertumbuhan aset bank syariah, namun tidak terdapat dalam model, yaitu displacement commercial risk, yaitu resiko beralihnya nasabah bank syariah ke bank konvensional, akibat tingkat bagi hasil yang rendah jika dibandingkan dengan tingkat suku bunga bank konvensional yang berlaku. Fenomena likuiditas bank konvensional yang memburuk akibat melambatnya pertumbuhan ekonomi (Febrianto, 2015:1), membuat bank konvensional meningkatkan suku bunga deposito. Hal tersebut memiliki efek pada preferensi masyarakat untuk beralih ke bank konvensional yang menawarkan tingkat pengembalian lebih tinggi. Fenomena ini membuat displacement commercial risk yang dihadapi oleh bank syariah semakin tinggi, hingga dapat menurunkan jumlah dana pihak ketiga dan mempengaruhi aset yang dimiliki bank syariah.

Selain itu, tidak adanya penerapan sistem bagi hasil yang sesuai dengan konsep murni menjadi penjelas tidak signifikannya faktor internal terhadap pertumbuhan aset bank syariah selanjutnya. Penentuan tingkat bagi hasil yang dilakukan oleh bank syariah pada praktiknya, masih menyesuaikan dengan tingkat suku bunga bank konvensional, sehingga tingkat bagi hasil bank syariah lebih sering disebut dengan tingkat bagi hasil ekuivalen. Ketika suku bunga bank konvensional tinggi, maka bank syariah akan meningkatkan rasio bagi hasil bagi nasabah agar setara dengan 
Aisy, et al/Jurnal Ekonomi Syariah Teori dan Terapan Vol. 3 No. 3 Maret 2016: 249-265; FAKTOR-FAKTOR YANG MEMPENGARUHI PERTUMBUHAN ASET BANK SYARIAH DI INDONESIA TAHUN 2006-2015

suku bunga yang diterapkan oleh bank konvensional. Hal tersebut dilakukan oleh bank syariah dengan tujuan untuk meminimalisir adanya commercial displacement risk. Namun, dampak yang ditimbulkan dari kebijakan tersebut yaitu tidak adanya perbedaan yang signifikan antara bank syariah dan bank konvensional, terutama dari sisi besarnya tingkat pengembalian yang diterima nasabah, sehingga menyebabkan masyarakat tidak memiliki alasan khusus untuk lebih memilih meletakkan dana di bank syariah daripada di bank konvensional. Secara tidak langsung hal tersebut akan mempengaruhi besaran dana pihak ketiga yang dihimpun oleh bank syariah, serta pertumbuhan aset yang dimiliki bank syariah.

Faktor eksternal akan lebih mempengaruhi pertumbuhan aset bank syariah melalui faktor internal bank syariah, dibandingkan pengaruhnya secara langsung terhadap pertumbuhan aset bank syariah. Pengaruh faktor eksternal terhadap pertumbuhan aset bank syariah, melalui faktor internal memiliki koefisien sebesar 0.063. Sedangkan, pengaruh faktor eksternal terhadap pertumbuhan aset bank syariah secara langsung memiliki koefisien sebesar 0.053.

\section{SIMPULAN}

Berdasarkan pada nilai analisis dan pengujian hipotesis, maka dapat diambil beberapa kesimpulan antara lain faktor eksternal memiliki pengaruh negatif signifikan terhadap faktor internal bank syariah di Indonesia sebesar 0.873; faktor eksternal tidak memiliki pengaruh signifikan terhadap pertumbuhan aset bank syariah di Indonesia;

faktor internal tidak memiliki pengaruh signifikan terhadap pertumbuhan aset bank syariah di Indonesia; serta Faktor-faktor dari yang paling mempengaruhi pertumbuhan aset bank syariah adalah faktor internal, faktor eksternal melalui faktor internal, serta faktor eksternal secara langsung.

\section{DAFTAR PUSTAKA}

Adawiyah, Wiwiek Rabiatul. 2010. Pertimbangan,, Pengetahuan, dan Sikap Konsumen Individu Terhadap Bank Syariah. Jurnal Ekonomi Pembangunan, Volume 11, Nomor 2 (12):191-201, (Online),

(http://download.portalgaruda.org/articl e.php? article $=354689 \& \mathrm{val}=8140 \&$ title $=P E$ RTIMBANGAN,\%20PENGETAHUAN,\%20DA N\%20SIKAP\%20KONSUMEN\%2OINDIVIDU\%2 OTERHADAP\%2OBANK\%2OSYARIAH, diakses pada 27 Januari 2016)

Alamsyah, Halim. 2012. Perkembangan dan Prospek Perbankan Syariah Indonesia: Tantangan Dalam Menyongsong MEA 2015. Makalah disampaikan dalam Ceramah IImiah Ikatan Ahli Ekonomi Islam (IAEI), Milad ke-8 IAEI, 13 April. 
Aisy, et al/Jurnal Ekonomi Syariah Teori dan Terapan Vol. 3 No. 3 Maret 2016: 249-265; FAKTOR-FAKTOR YANG MEMPENGARUHI PERTUMBUHAN ASET BANK SYARIAH DI INDONESIA TAHUN 2006-2015

Anshori, Muslich dan Sri Iswati. 2009. Buku Ajar Metodolodi Penelitian Kuantitatif. Surabaya: Pusat Penerbitan dan Percetakan Unair (AUP).

Antonio, Muhammad Syafi'i. 1999. Bank Syariah Bagi Bankir \& Praktisi Keuangan. Jakarta: Bank Indonesia bekerja sama dengan Tazkia Institute.

2004. Bank Syariah Dari Teori Ke Praktik. Jakarta: Gema Insani.

Arafah, Rahmat. 2015. Faktor Internal dan Eksternal Yang Mempengaruhi Pertumbuhan Dana Pihak Ketiga Bank Syariah Di Indonesia. Skripsi tidak diterbitkan. Surabaya Fakultas Ekonomi Dan Bisnis Universitas Airlangga.

Arifin, Zainul. 2002. Dasar-Dasar Manajemen Bank Syariah. Jakarta: Pustaka Alvabet.

Ascarya. 2007. Akad \& Produk Bank Syariah. Jakarta: PT. RajaGrafindo Persada.

Badan Pusat Statistik. 2014. Laju Pertumbuhan PDB Pengeluaran Kumulatif 2001-2014, (Online), (http://www.bps.go.id/linkTabelStatis/vie w/id/1202, diakses pada 27 November 2015)

Bank Indonesia. 2012. Kodifikasi Peraturan Bank Indonesia Kelembagaan Penliaian Tingkat Kesehatan Bank, (Online), (http://www.bi.go.id/id/peraturan/kodifik asi/bank/Documents/KodifikasiPenilaian\%20Tingkat\%20Kesehatan\%20Ba nk.pdf, diakses 27 November 2015).
Bungin, Burhan. 2005. Metodologi Penelitian Kuantitatif. Edisi Pertama. Jakarta: Prenada Media.

Chapra, M. Umer. 2000. Sistem Moneter Islam. Diterjemahkan oleh Ikhwan Abidin Basri. Jakarta: Gema Insani.

Daft, Richard L. 2010. Era Baru Manajemen. Edisi Ke-9. Buku 1. Diterjemahkan oleh Tita Maria Kanita. Jakarta: Salemba Empat.

David, Fred R. 2009. Manajemen Strategis. Edisi Ke-12. Buku 1. Diterjemahkan oleh Dono Sunardi. Jakarta: Salemba Empat.

Febrianto, Heru. 2015, 28 April. Ekonomi Indonesia Melambat Likuiditas Perbankan Merosot. Sindonews.com, (Online),

(http://ekbis.sindonews.com/read/99450

5/178/ekonomi-indonesia-melambat-

likuiditas-perbankan-merosot-1430139603, diakses pada 29 Januari 2016)

Ghozali, Imam. 2008. Metode Alternatif Dengan Partial Least Sauare (PLS). Edisi Kedua. Semarang: Badan Penerbit Universitas Diponegoro.

Hasan, labal. 2008. Pokok-Pokok Materi Statistik I (Statistik Deskriptif). Jakarta: Bumi Aksara.

Hasan, Nurul Ichsan. 2014. Pengantar Perbankan. Jakarta: Gaung Persada Press Group.

Idrus, Muhammad. 2009. Metode Penelitian IImu Sosial Pendekatan Kualitatif dan Kuantitatif. Edisi Kedua. Jakarta: Penerbit Erlangga. 
Aisy, et al/Jurnal Ekonomi Syariah Teori dan Terapan Vol. 3 No. 3 Maret 2016: 249-265; FAKTOR-FAKTOR YANG MEMPENGARUHI PERTUMBUHAN ASET BANK SYARIAH DI INDONESIA TAHUN 2006-2015

Ihsan, Muntoha. 2011. Pengaruh Gross Domestic Product, Inflasi, dan Kebijakan Jenis Pembiayaan Terhadap Rasio Non Performong Financing Bank Umum Syariah Di Indonesia Periode 2005 Sampai 2010. Skripsi tidak diterbitkan. Semarang Fakultas Ekonomi Universitas Diponegoro. Ikatan Akuntan Indonesia. 2007. Pernyataan Standar Akuntansi Kevangan No. 101 Penyajian Laporan Kevangan Syariah. Jakarta: Dewan Standar Akuntansi Keuangan.

---------. 2007. Kerangka DasarPenyusunan

Dan Penyajian Laporan Kevangan Syariah. Jakarta: Dewan Standar Akuntansi Keuangan.

Indriani, Latti. 2006. Analisis Faktor-Faktor

Yang Mempengaruhi Pertumbuhan Total Aset Bank Syariah Di Indonesia. Skripsi Sarjana pada Fakultas Ekonomi dan Manajemen Institut Pertanian Bogor: tidak diterbitkan.

Ismail. 2011. Perbankan Syariah. Edisi

Pertama. Jakarta:Kencana.

Jaya, I Gede N.M. dan I Made Sumertajaya.

2008. Permodelan Persamaan Struktural

Dengan Partial Least Square. Jurnal Semnas Matematika dan Pendidikan Matematika 2008, (Online), (http://eprints.uny.ac.id/6856/, diakses 25 Oktober 2015).

Karim, Adiwarman A. 2004. Bank Islam Analisis Fiqih dan Keuangan. Edisi Kelima. Jakarta: PT. RajaGrafindo Persada.
-------. 2007. Ekonomi Makro Islami. Edisi Kedua. Jakarta: PT. RajaGrafindo Persada.

Kasmir. 2008. Analisis Laporan Keuangan. Jakarta: PT. RajaGrafindo Persada.

Kementrian Agama Republik Indonesia. 1987. Pedoman Transliterasi Arab-Latin. Keputusan Bersama Menteri Agama dan Menteri P dan K Nomor 158 Tahun 1987. (Online).

(http://lajnah.kemenag.go.id/buku/undu h/category/15-

transliterasi? download=49:skb-tentangpedoman-transliterasi-arab-latin, diakses pada 1 Desember 2015)

Kusviandita, Mohammad Alfian. 2015. Pengaruh Sukuk Terhadap Kinerja Perusahaan Dan Kinerja Saham Emiten Yang Terdaftar Di Bursa Efek Indonesia (BEI) Tahun 2009-2013. Skripsi tidak diterbitkan. Surabaya Fakultas Ekonomi dan Bisnis Universitas Airlangga.

Latan, Hengky dan Imam Ghozali. 2013. Partial Least Square, Konsep Aplikasi Path Modelling. Semarang: Badan Penerbit Universitas Diponegoro.

Mishkin, Frederic S. 2008. Ekonomi Uang, Perbankan, dan Pasar Keuangan. Edisi Ke-8. Buku 1. Terjemahan oleh Lina Soelistianingsih dan Beta Yulianita $G$. Jakarta: Salemba Empat.

--------. 2009. Ekonomi Uang, Perbankan, dan Pasar Keuangan. Edisi Ke-8. Buku 2. Terjemahan oleh oleh Lina Soelistianingsih 
Aisy, et al/Jurnal Ekonomi Syariah Teori dan Terapan Vol. 3 No. 3 Maret 2016: 249-265; FAKTOR-FAKTOR YANG MEMPENGARUHI PERTUMBUHAN ASET BANK SYARIAH DI INDONESIA TAHUN 2006-2015

dan Beta Yulianita G. Jakarta: Salemba Empat.

Muhammad. 2002. Manajemen Bank Syari'ah. Yogyakarta: Unit Penerbit dan percetakan (UPP) AMP YKPN.

2004. Manajemen Dana Bank

Syari'ah. Edisi Pertama. Yogyakarta:

Ekonisia.

2005. Manajemen Bank Syari'ah.

Edisi Revisi. Yogyakarta: Unit Penerbit dan percetakan (UPP) AMP YKPN.

Otoritas Jasa Keuangan. 2015. Statistik

Perbankan Syariah Tahun 2003-2015,

(Online),

(http://www.ojk.go.id/id/kanal/syariah/d

ata-dan-statistik/statistik-perbankan-

syariah/Default.aspx, diakses pada 27

November 2015).

Riduwan. 2010. Dasar-Dasar Statistika. Bandung: Alfabeta.

Sahara, Ayu Yanita. 2013. Analisis Pengaruh Inflasi, Suku Bunga Bl, dan Produk Domestim Bruto Terhadap Return On Asset (ROA) Bank Syariah Di Indonesia. Jurnal Ilmu Manajemen, Volume 1, Nomor 1 (1):149-157, (Online), (http://ejournal.unesa.ac.id/index.php/ji m/article/view/1502, diakses 1 Desember 2015)

Soemitro, Andri. 2009. Bank dan Lembaga Kevangan Syariah. Jakarta: Kencana.

Sukirno, Sadono. 1994. Makroekonomi Teori Pengantar. Edisi Ketiga. Jakarta: PT. RajaGrafindo Persada.
-------. 2000. Makroekonomi Modern, Perkembangan Pemikiran Dari Klasik Hingga Keynesian Baru. Jakarta: PT. RajaGrafindo Persada.

Syafrida, Ida dan Ahmad Abror. 2011. Faktor-Faktor Internal Dan Eksternal Yang Mempengaruhi Pertumbuhan Aset Perbankan Syariah Di Indonesia. Jurnal Ekonomi Dan Bisnis, Volume 10, Nomor 1 (6):19-24, (Online), (http://jurnalpnj.com/index.php/ekbis/art icle/view/468/pdf_28, diakses pada 1 Desember 2015). 